\title{
Selecting a Contractor by Using a Novel Method for Multiple Attribute Analysis: Weighted Aggregated Sum Product Assessment with Grey Values (WASPAS-G)
}

\author{
Edmundas Kazimieras ZAVADSKAS, Zenonas TURSKIS, Jurgita ANTUCHEVICIENE \\ Vilnius Gediminas Technical University, \\ Sauletekio al. 11, LT-10223 Vilnius, Lithuania, \\ edmundas.zavadskas@vgtu.lt; zenonas.turskis@vgtu.lt; jurgita.antucheviciene@vgtu.lt
}

\begin{abstract}
Selecting the right contractor in construction industry is an important problem for an organization while the competition in global markets increases. Evaluating contractors' performance is a multiple attribute decision making process consisting of vagueness and imprecision. It is based on a set of hardly exact measurable attributes: capability and skills, occupational health and safety, technical capacity, managerial capability, bid amount, past performance and experience, financial soundness. The goals and interests of the stakeholders should be taken into consideration when selecting the attributes and their importance for the evaluation of contractors. In this context, the paper presents a novel method based on multiple attribute Weighted Aggregated Sum Product Assessment with the grey attributes scores WASPAS-G method. The proposed method was applied in a case study of evaluation and selection of a right construction contractor, which has to be the most appropriate to stakeholders. The proposed technique, due to its capabilities of handling imprecise information because of applied grey relations and capabilities of providing decisions of enhanced accuracy when aggregating two methods, could also be used to sustain the ranking of development strategies, selecting the most effective investment or management decisions.
\end{abstract}

Keywords: Multiple Attribute Decision Making (MADM), contractor selection, Weighted Aggregated Sum Product Assessment (WASPAS), grey relations, WASPAS-G.

\section{Introduction}

Construction Industry Development Board (CIDB) reported that contractors waste up to $10 \%$ of the project costs when acting in a wrong way and correcting these wrong actions later. Most of construction projects involve risks that are difficult to control and analyse [1].

Contractor selection has attributes both qualitative and quantitative in nature. Construction cost and time overrun is a common problem in construction industries [2]. This is because of the sixteen following main factors: a) no clearly defined scope of project in the contract, b) no proper cost control, c) contract dispute (unclear drawings and / or guideless regulations), d) high fluctuation in commodity prices, e) the gap between construction plan and reality is too great, f) material shortage or supply delay, g) time management, h) practical experience, I) modifications of the scope of construction, $j$ ) the level of demand quality, k) project team, 1) project valuation does not match the collected payment, m) procurement contract, n) geology and topography, o) climate factor, p) natural disasters.
Abbasianjahromi et al. [3] argued that present condition of the construction industry imposes onerous responsibilities on contractors so they are very eager to subcontract some of their works. Therefore, subcontracting also should to be taken into account when selecting proper construction contractor [4].

Comprehensive evaluation and proper selection of the right contractor is an important decision that has a huge impact on the overall success of a construction project. Accordingly, there is a necessity for decision support methods to assist stakeholders in making optimal decisions when selecting a contractor [5].

The standard optimisation techniques could be applied when: a) the rules of the game are well laid out; b) the environment is predictable; c) actors behaviour is deterministic; d) costs vary within a small, narrow band, and e) relationships between variables are linear.

However, deciding whether to bid on a project is commonly referred to as the bid/no-bid decision. It is a critical activity associated with complexity as well as uncertainty. Various multi-attribute decision-making methods are now available to help stakeholders in choosing the best decisive course of actions, including those for evaluation of contractors [6 - 8], 
supporting products and services acquisition [9], technology [10] or software selection [11]. Some of the models that involve both monetary and non-monetary criteria can be partly considered as multi-attribute decision-making models [12 - 14], but they do not provide a mathematical formulation and an optimization model as their basis for decision-making [15]. The benefits of the above-mentioned actions in construction industry are unpredictable, relationships between attributes may be actually unknown [16]. Furthermore, modelling real-world problems with crisp values of attributes under many conditions is inadequate because human judgement and his preferences are often vague and implicit and hardly can be estimated with exact numerical values [17].

To overcome the listed shortcomings, the paper presents a novel multiple attribute Weighted Aggregated Sum Product Assessment method with the grey attributes scores - WASPAS-G method. The advantages of the proposed technique are based on its capabilities of handling imprecise information due to applied grey relations and capabilities of providing decisions of enhanced accuracy when optimizing weighted aggregated assessment. The proposed novel method is applied in a case study of evaluation and selection of a right contractor from a set of potential construction contractors.

The paper is organized as follows. Chapter 2 presents preliminaries of grey theory. The main recent applications of grey extensions of MADM (Multiple Attribute Decision Making) methods in construction engineering and management are shortly reviewed in Chapter 3. Introduction to WASPAS method and development of WASPAS-G method is presented in Chapter 4. Chapter 5 contains case study of construction contractor selection by applying the novel multiple attribute decision making method.

\section{Grey Theory Preliminaries}

Grey theory is a technique designed for performing prediction and decision-making in many activities. Deng [18] introduced the concepts of grey theory from a grey set by combining concepts of system theory, space theory and control theory.

Let's start from the fact that information can be classified to three groups based on uncertainty level of initial data and named as white numbers, grey numbers and black numbers [19]. Let

$$
\otimes x=[\alpha, \beta]=|x| \alpha \leq x \leq \beta, \alpha \text { and } \beta \in R \mid .
$$

From the above equation one can see that $\otimes x$ consists of two real numbers: $\alpha$ is the lower limit and $\beta$ is the upper limit. Based on the conditions bellow, $\otimes x$ can be classified as follows:

- if $\alpha=\beta$, then $\otimes x$ is a usual crisp number with complete information and it can be called the white number;

- else if $\alpha \rightarrow-\infty$ and $\beta \rightarrow \infty$, then $\otimes x$ contains no meaningful information and it can be called the black number;

- otherwise $\otimes x=\lfloor\alpha, \beta \mid$ is called the grey number which means and uncertain, incomplete or insufficient information.

Usually in many cases information in real world problems is uncertain or incomplete. Consequently, extending the crisp methods with white numbers to applications with grey numbers is actually inevitable for real world decisions.

In order to apply grey arithmetic, a set of operations on grey numbers should be defined. The basic definitions and operations of two grey numbers are described as follows.

As it was described above, let a grey number to be defined by two parameters $(\alpha, \beta)$. Let ,,$+- \times$ and $\div$ denote the operations of addition, subtraction, multiplication and division, respectively. Some of the main operations of positive grey numbers $\otimes n_{1}$ and $\otimes n_{2}$ can be expressed as follows [20]:

Addition

$\otimes n_{1}+\otimes n_{2}=\left(n_{1 \alpha}+n_{2 \alpha}, n_{1 \beta}+n_{2 \beta}\right)$,

Subtraction

$\otimes n_{1}-\otimes n_{2}=\left(n_{1 \alpha}-n_{2 \beta}, n_{1 \beta}-n_{2 \alpha}\right)$,

Multiplication

$\otimes n_{1} \times \otimes n_{2}=\left(n_{1 \alpha} \times n_{2 \alpha}, n_{1 \beta} \times n_{2 \beta}\right)$,

Division

$\otimes n_{1} \div \otimes n_{2}=\left(\frac{n_{1 \alpha}}{n_{2 \beta}}, \frac{n_{1 \beta}}{n_{2 \alpha}}\right)$

only if $n_{1 \alpha}, n_{2 \alpha}, n_{1 \beta}$ and $n_{2 \alpha}$ does not contain 0 
Multiplication of grey numbers by a positive real number $(k)$

$$
k \times\left(\otimes n_{1}\right)=\left(k n_{1 \alpha}, k n_{1 \beta}\right),
$$

Exponentiation by a natural power

$$
\begin{aligned}
& \left(\otimes n_{1}\right)^{-1}=\left(\frac{1}{n_{1 \beta}}, \frac{1}{n_{1 \alpha}}\right), \\
& \left(\otimes n_{1}\right)^{k}=\left(\left(n_{1 \alpha}\right)^{k},\left(n_{1 \beta}\right)^{k}\right), \text { if } n_{1 \alpha} \text { and } n_{1 \beta}<1, \text { and } k>1, \\
& \left(\otimes n_{1}\right)^{k}=(1,1), \text { if } n_{1 \alpha} \text { and } n_{1 \beta}<1, \text { and } k=0
\end{aligned}
$$

Instead of working with an uncertain real $x$ and applying classical arithmetic operations, a decision maker works with the grey numbers and grey arithmetic. Grey arithmetic is a powerful tool for reliable computing, and has been successfully used in the past. Recently, grey theory found a new field of applications when extending usual crisp methods, including multiple attribute decision making methods.

\section{Recent Applications of Grey Extensions of MADM Methods}

Grey theory can be successfully amalgamated with many of the decision-making processes so as to improve the quality of judgments. It is suitable for expressing quantitative but imprecise data. Also ambiguity in dealing with imprecise data can be reduced through linguistic assessment of attributes. The linguistic assessments can also be converted into associated grey values.

Below are listed some of the recent applications of interval extensions of MADM methods in civil engineering and management.

Additive Ratio ASsessment (ARAS) method with the grey attribute scores - ARAS-G, in combination with Delphi and AHP (Analytic Hierarchy Process) methods was applied by Turskis et al. [21] for improving the built and human environment through efficient decision making in renovation of urban cultural heritage. The methods enabled to combine successfully different external factors as well as stakeholders' preferences.

Siozinyte et al. [22] applied TOPSIS-grey (Technique for Order Preference by Similarity to Ideal Solution with attributes values determined at intervals) for selecting user and environment friendly redevelopment decisions of vernacular building, involving assessment of preserved features of vernacular architecture and assuring the enforcement of contemporary building norms.
Oztaysi [23] presented selection of Content Management System among available alternatives as a multi-attribute decision making problem. A decision model built by integrating AHP and TOPSIS-grey method was proposed and applied in a foreign trade company. Besides, the effects of using different distance functions, such as Manhattan, Euclidian and Minkowski distance functions are analysed in the paper.

Zhang et al. [24] proposed an improved TOPSIS method based on weighted grey relational coefficient to evaluate and compare service quality of nine airlines and compares. The method integrates the advantage of usual TOPSIS and grey relational analysis on the curve position and the curve trend within treatment of data sequences. Authors provide a G-AHP method to determine weights, which combines the latent roots method with AHP.

Kim et al. [25] performed multi-attribute mixed type decision making by four methods, including the relative approach degree of grey TOPSIS method, the relative approach degree of grey incidence, the relative membership degree of grey incidence and the grey relation relative approach degree method using the maximum entropy estimation, respectively. In these decision making methods, the grey incidence degree in four-dimensional Euclidean space is used. The final arrangement result is obtained by weighted Borda method.

Tavana et al. [26] applied two MADM tools including fuzzy ANP (Analytic Network Process) and COPRAS-G (COmplex PRoportional Assessment) of alternatives with Grey relations, for social media platform evaluation and selection.

Nguyen et al. [27] presented hybrid approach that is also based on fuzzy ANP and COPRAS-G for multiple attribute decision making under uncertainty. Machine tools were evaluated, considering the interactions of the attributes with the help of ANP. The result is then compared with the rankings provided by other methods with grey numbers, such as TOPSIS-G, SAW-G (Simple Additive Weighting with grey numbers) and GRA (Grey Relational Analysis).

The grey-based PROMETHEE II (Preference Ranking Organization METhod for Enrichment Evaluation) methodology is designed to represent and analyse decision problems under uncertainty, which are characterized by limited 
input data and uncertain preferences of decision makers. The methodology is illustrated using a case study in which source water protection strategies are ranked for Waterloo Region, Canada [28].

Stanujkic et al. [29] extended MOORA (MultiObjective Optimization on the basis of Ratio Analysis) with performance ratings of alternatives expressed as interval grey numbers. The novel method was applied for circuit design selection in mineral processing operations. Circuit design selection was also solved by applying fuzzy MOORA [30].

It is interesting to mention that Hashemi et al. [31] extended the ELECTRE (ELimination Et Choix Traduisant la REalité, that means Elimination and Choice Expressing Reality) method with black numbers containing no meaningful information. The proposed method was applied in a supplier selection problem under ambiguous environment.

Some other extensions of crisp multiple attribute decision making methods under uncertain conditions of contractor or supplier selection are also available in recent publications. For example, Senthil et al. [32] proposed a hybrid method using AHP and fuzzy TOPSIS for contractor evaluation and selection in third-party reverse logistics. You et al. [33] proposed an extended VIKOR (VIseKriterijumska Optimizacija I Kompromisno Resenje, that means Multicriteria Optimization and Compromise Solution) method for group multi-criteria supplier selection with interval 2-tuple linguistic information. The feasibility and practicability of the proposed ITL-VIKOR method are demonstrated through three realistic supplier selection examples and comparisons with the existing approaches.

\section{WASPAS-G Method}

\subsection{WASPAS method and its applications}

Zavadskas et al. [34] proposed and originally described Weighted Aggregated Sum Product Assessment (WASPAS) method. The method aggregates the Weighted Sum Model (WSM) and the Weighted Product Model (WPM) with the help of originally derived aggregation coefficient, enabling to reach the highest accuracy of multiple attribute estimation of a problem.
There are lots of WASPAS method applications for solving MADM problems in construction. WASPAS and ARAS methods were used to evaluate potential alternatives of potential shopping mall locating by Hashemkhani Zolfani et al. [35]. Dejus and Antucheviciene [36] suggested using the WASPAS method for ranking of appropriate alternatives for occupational safety. Zavadskas et al. [37] presented an application of the method for multi-attribute assessment of public building designs alternatives, while Siozinyte and Antucheviciene [38] applied the method for assessment of windows' design when upgrading vernacular buildings. Bagocius et al. [39] applied WASPAS method for ranking and selecting the best location for wind farms and assessing the types of wind turbines. While Vafaeipour et al. [40] used the same method of assessment in combination with Step-wise Weight Assessment Ratio Analysis (SWARA) for prioritizing regions and cities for location of solar power plants in the future. Lashgari et al. [41] applied Quantitative Strategic Planning Matrix and WASPAS method that enabled to make reasoned decision in selecting the best strategies for outsourcing development. The first attempt to extend the method for problems involving uncertainty was presented as WASPAS-IVIF [42].

Based on literature review that involves development and applications mostly of a crisp method under consideration, the authors suggest that grey extension of WASPAS method is feasible for most effective real world applications. The development of a novel WASPAS-G method is presented below in the following sub-section.

\subsection{WASPAS with grey values}

Previously developed WASPAS method is derived on the basis of two MADM methods, i.e. WSM (Weighted Sum Model) and WPM (Weighted Product Model), aggregating them with the help of originally described optimized weighting coefficient [34].

To extend the method in vague environment with the help of grey numbers, initial decision making matrix should be presented as a grey decision-making matrix (GDMM). Matrix is composed on the basis of preferences of decision alternatives rated on attributes: 


$$
\otimes X=\left[\begin{array}{lllll}
\otimes x_{11} & \cdots & \otimes x_{1 j} & \cdots & \otimes x_{1 n} \\
\vdots & \ddots & \vdots & \ddots & \vdots \\
\otimes x_{i 1} & \cdots & \otimes x_{i j} & \cdots & \otimes x_{i n} \\
\vdots & \ddots & \vdots & \ddots & \vdots \\
\otimes x_{m 1} & \cdots & \otimes x_{m j} & \cdots & \otimes x_{m n}
\end{array}\right]
$$

where $m$ - number of alternatives, $n$ - number of attributes, $i=1, \ldots, m, j=1, \ldots, n$; $\otimes x_{i j}-$ denotes the grey evaluations of the $i$-th alternative with respect to the $j$-th attribute.

Next, the initial values of all the attributes should be normalized. Normalized grey evaluations of each alternative with respect to every attribute are defined as $\otimes \bar{x}_{i j}, i=1, \ldots, m$; $j=1, \ldots, n$, while grey initial matrix $\otimes X$ is transformed to grey normalised decisionmaking matrix $\otimes \bar{X}$ :

$$
\otimes \bar{X}=\left|\begin{array}{lllll}
\otimes \bar{x}_{11} & \cdots & \otimes \bar{x}_{1 j} & \cdots & \otimes \bar{x}_{1 n} \\
\vdots & \ddots & \vdots & \ddots & \vdots \\
\otimes \bar{x}_{i 1} & \cdots & \otimes \bar{x}_{i j} & \cdots & \otimes \bar{x}_{i n} \\
\vdots & \ddots & \vdots & \ddots & \vdots \\
\otimes \bar{x}_{m 1} & \cdots & \otimes \bar{x}_{m j} & \cdots & \otimes \bar{x}_{m n}
\end{array}\right|
$$

As WSM and WPM methods use a linear normalization approach, corresponding values of attributes in the derivative method are also normalized by applying a linear method, adapted for grey values. Attributes with preferred maximal values are normalized as

$$
\begin{aligned}
& \otimes \bar{x}_{i j}=\frac{\otimes x_{i j}}{\max _{i} \otimes x_{i j}}, \\
& \text { i.e. } \bar{x}_{i j \alpha}=\frac{x_{i j \alpha}}{\max _{i} x_{i j \beta}} \text { and } \bar{x}_{i j \beta}=\frac{x_{i j \beta}}{\max _{i} x_{i j \beta}} .
\end{aligned}
$$

Attributes with preferred minimal values are suggested to be normalized as follows:

$$
\begin{aligned}
& \otimes \bar{x}_{i j}=\frac{\min _{i} \otimes x_{i j}}{\otimes x_{i j}}, \\
& \text { i.e. } \bar{x}_{i j \alpha}=\frac{\min _{i} x_{i j \alpha}}{x_{i j \beta}} \text { and } \bar{x}_{i j \beta}=\frac{\min _{i} x_{i j \alpha}}{x_{i j \alpha}} .
\end{aligned}
$$

In the following stage the weights of attributes should be involved in the future assessment. Weights of attributes $\otimes w_{j}$ denote the relative significance of the attributes, $0<\otimes w_{j}<1$, $\sum_{j=1}^{n} w_{j}=1$. Weights are also expressed with the help of grey numbers, because they reflect a partly subjective assessment of importance of attributes, usually obtained using expert evaluation methods.

The next task is to determine grey values of optimality functions. The grey value $\otimes S_{i}$ of additive optimality function (WSM) for $i$ alternative is calculated as follows:

$$
\begin{aligned}
& \otimes S_{i}=\sum_{j=1}^{n} \otimes \hat{x}_{i j}, j=1, \ldots, m, \text { or } \\
& \otimes S_{i}=0.5 \sum_{j=1}^{n}\left(\hat{x}_{i j \alpha}+\hat{x}_{i j \beta}\right),
\end{aligned}
$$

where $\otimes \hat{x}_{i j}$ is normalized weighted value of the attribute. It is calculated as follows:

$$
\otimes \hat{x}_{i j}=\otimes \bar{x}_{i j} \times \otimes w_{j},
$$

where $\otimes w_{j}$ is the grey weight of the $j$ attribute and $\otimes x_{i j}$ is the grey normalized rating of the $i$ th alternative with respect to the $j$-th attribute.

The grey value $\otimes P_{i}$ of optimality function according to WPM is as follows:

$$
\begin{aligned}
& \otimes P_{i}=\prod_{j=1}^{n} \otimes \bar{x}^{\otimes w_{j}}, j=1, \ldots, m, \text { or } \\
& \otimes P_{i}=\prod_{j=1}^{n} 0.5\left(\otimes \bar{x}_{j \alpha}^{\otimes w_{j}}+\otimes \bar{x}_{j \beta}^{\otimes w_{j}}\right)
\end{aligned}
$$

where $\otimes w_{j}$ is the grey weight of the $j$ attribute and $\otimes x_{i j}$ is the grey normalized rating of the of the $i$-th alternative with respect to the $j$-th attribute.

Supposing the increase of effectiveness of decisions and following the previous research [34], the weighted aggregation of grey functions is proposed:

$$
\begin{aligned}
& \otimes Q_{i}=\lambda \sum_{j=1}^{n} \otimes \hat{x}_{i j}+(1-\lambda) \prod_{j=1}^{n} \otimes \bar{x}^{\otimes w_{j}} \\
& \lambda=0, \ldots, 1 .
\end{aligned}
$$

It is proposed to determine $\lambda$ based on assumption that total WSM grey scores should to be equal to the total of WPM grey scores for all alternatives:

$$
\lambda=0.5 \frac{\sum_{i=1}^{m} P_{i}}{\sum_{i=1}^{m} S_{i}}
$$

where grey values are transformed to crisp values by using the centre-of-area method, i.e.

$$
\begin{aligned}
& P_{i}=0.5\left(P_{i \alpha}+P_{i \beta}\right), \\
& S_{i}=0.5\left(S_{i \alpha}+S_{i \beta}\right)
\end{aligned}
$$


The grey values of $\otimes Q_{i}$ can be also transformed to crisp values by the centre-ofarea method.

The decreasing preference order of the alternatives is determined according to the decreasing sequence of $Q_{i}$.

\section{Case Study of Contractor Selection}

\subsection{Problem formulation}

Modern projects are normally characterised by huge investments, long construction periods, and complex technology. However, correlation among attributes, subjectivity of attributes weights, and heterogeneity among experts' professional capabilities for selecting contractors could not be successfully removed from the decision-making process [43]. Consequently, it is suggested that the problem be presented as GDMM and appropriate methods for evaluating and selecting contractors should also be applied.

The investing construction owner has to decide which contractors best meet his/her requirements. Based on a numerous key criteria or attributes for contractors' evaluation that can be found in a literature [44, 45] and after interviewing purchase managers of construction companies, 6 main attributes (aggregating sub-attributes) were identified for contractor selection:

$x_{1}$ : Bid amount. It includes four main subattributes (advance payment, capital bid, routine maintenance and major repairs).

$x_{2}$ : Capability and skill, occupational health and safety. It describes contractor's potential capacity to produce a good or service, at the same time effectively managing risk to the health and safety of his employees.

$x_{3}$ : Technical capacity. It shows abilities to provide high quality goods, to act in the specific project and ensure future developments.

$x_{4}$ : Managerial capability. Decision maker should be sure that the contractor would be able to manage activities, i.e. to plan, organize and control the project.

$x_{5}$ : Past performance and experience. It includes data and opinion about the past performance of the contractor, the historical experiments of working with special projects and the amount of satisfaction or dissatisfaction. Also the attribute includes contractor's attitudes towards continuous training and education.

$x_{6}$ : Financial soundness. It includes four main sub-attributes as financial stability, credit rating, bank arrangement, and bonding and financial status.

Linguistic variables for grey weighting attributes are presented in Table 1. Relative importance of the listed attributes is determined by expert method. A sample of 37 experts was selected. Consistency of their ratings was found to be sufficient at a significance level $=0.05$, therefore aggregated attribute weights were calculated and listed in Table 2.

Four of the possible alternatives of contractors under consideration $A_{i}, i=1, \ldots, 4$ are compared in accordance with 6 attributes and are presented in Table 3.

\subsection{Results of multiple attribute analysis}

The initial values of attributes were transformed to dimensionless values by applying linear normalization for grey numbers (formulae 10,11) and processed applying the further steps of WASPAS-G method (formulae 12-17). The main stages of the solution process, including partial and final ranking of contractors are presented in Tables 4-6.

Table 1. The linguistic variables or the ratings

\begin{tabular}{|c|c|c|}
\hline \multirow{2}{*}{ Linguistic variables } & \multicolumn{2}{|c|}{ Grey numbers } \\
\cline { 2 - 3 } & $\boldsymbol{\alpha}$ & $\boldsymbol{\beta}$ \\
\hline Very Low (VL) & 0.000 & 0.200 \\
\hline Low (L) & 0.100 & 0.300 \\
\hline Medium Low (ML) & 0.200 & 0.400 \\
\hline Medium (M) & 0.350 & 0.650 \\
\hline Medium High (MH) & 0.600 & 0.800 \\
\hline High (H) & 0.700 & 0.900 \\
\hline Very High (VH) & 0.800 & 1.000 \\
\hline
\end{tabular}


Table 2. The attributes for evaluation of contractors' selection

\begin{tabular}{|c|c|c|c|c|c|}
\hline \multicolumn{2}{|c|}{ Attributes } & \multirow{2}{*}{ Measure units } & \multirow{2}{*}{ Opt. } & \multicolumn{2}{c|}{ Weight } \\
\cline { 5 - 6 } \multicolumn{2}{|c|}{} & & & $\boldsymbol{\alpha}$ & $\boldsymbol{\beta}$ \\
\hline$x_{1}$ & Bid amount & points & $\max$ & 0.195 & 0.245 \\
\hline$x_{2}$ & Capability and skill, occupational health and safety & points & $\max$ & 0.109 & 0.129 \\
\hline$x_{3}$ & Technical capacity & points & $\max$ & 0.156 & 0.210 \\
\hline$x_{4}$ & Managerial capability & points & $\max$ & 0.137 & 0.182 \\
\hline$x_{5}$ & Past performance and experience & points & $\max$ & 0.146 & 0.196 \\
\hline$x_{6}$ & Financial soundness & points & $\max$ & 0.137 & 0.158 \\
\hline
\end{tabular}

Table 3. Initial grey decision making matrix

\begin{tabular}{|c|c|c|c|c|c|c|c|c|c|c|c|c|}
\hline \multirow{4}{*}{} & \multicolumn{2}{|c|}{$\otimes x_{1}$} & \multicolumn{2}{c|}{$\otimes x_{2}$} & \multicolumn{2}{c|}{$\otimes x_{3}$} & \multicolumn{2}{c|}{$\otimes x_{4}$} & \multicolumn{2}{c|}{$\otimes x_{5}$} & \multicolumn{2}{c|}{$\otimes x_{6}$} \\
\cline { 2 - 13 } & \multicolumn{2}{|c|}{$\max$} & \multicolumn{2}{c|}{$\max$} & \multicolumn{2}{c|}{$\max$} & \multicolumn{2}{c|}{$\max$} & \multicolumn{2}{c|}{$\max$} & \multicolumn{2}{c|}{$\max$} \\
\cline { 2 - 13 } & $\alpha$ & $\beta$ & $\alpha$ & $\beta$ & $\alpha$ & $\beta$ & $\alpha$ & $\beta$ & $\alpha$ & $\beta$ & $\alpha$ & $\beta$ \\
\hline$w$ & 0.195 & 0.245 & 0.109 & 0.129 & 0.156 & 0.210 & 0.137 & 0.182 & 0.146 & 0.196 & 0.137 & 0.158 \\
\hline$A_{1}$ & 0.632 & 0.867 & 0.470 & 0.600 & 0.663 & 0.810 & 0.430 & 0.750 & 0.650 & 0.860 & 0.315 & 0.615 \\
\hline$A_{2}$ & 0.532 & 0.773 & 0.750 & 0.875 & 0.512 & 0.740 & 0.340 & 0.550 & 0.660 & 0.820 & 0.555 & 0.863 \\
\hline$A_{3}$ & 0.507 & 0.845 & 0.550 & 0.780 & 0.659 & 0.830 & 0.550 & 0.860 & 0.830 & 0.916 & 0.375 & 0.690 \\
\hline$A_{4}$ & 0.725 & 0.863 & 0.670 & 0.900 & 0.709 & 0.897 & 0.320 & 0.670 & 0.720 & 0.875 & 0.405 & 0.735 \\
\hline
\end{tabular}

Table 4. Normalised grey decision making matrix and solution results $P_{i}$

\begin{tabular}{|l|l|l|l|l|l|l|l|l|l|l|l|l|r|r|}
\hline & \multicolumn{2}{|c|}{$\otimes \bar{x}_{1}$} & \multicolumn{2}{c|}{$\otimes \bar{x}_{2}$} & \multicolumn{2}{c|}{$\otimes \bar{x}_{3}$} & \multicolumn{2}{|c|}{$\otimes \bar{x}_{4}$} & \multicolumn{2}{|c|}{$\otimes \bar{x}_{5}$} & $\otimes \bar{x}_{6}$ & $\boldsymbol{P}_{i}$ & Rank \\
\hline$w$ & 0.195 & 0.245 & 0.109 & 0.129 & 0.156 & 0.210 & 0.137 & 0.182 & 0.146 & 0.196 & 0.137 & 0.158 & & \\
\hline$A_{1}$ & 0.729 & 1.000 & 0.522 & 0.667 & 0.739 & 0.903 & 0.500 & 0.872 & 0.710 & 0.939 & 0.365 & 0.713 & 0.670 & $3-4$ \\
\hline$A_{2}$ & 0.614 & 0.892 & 0.833 & 0.972 & 0.571 & 0.825 & 0.395 & 0.640 & 0.721 & 0.895 & 0.643 & 1.000 & 0.670 & $3-4$ \\
\hline$A_{3}$ & 0.585 & 0.975 & 0.611 & 0.867 & 0.735 & 0.925 & 0.640 & 1.000 & 0.906 & 1.000 & 0.435 & 0.800 & 0.747 & 1 \\
\hline$A_{4}$ & 0.836 & 0.995 & 0.744 & 1.000 & 0.790 & 1.000 & 0.372 & 0.779 & 0.786 & 0.955 & 0.469 & 0.852 & 0.717 & 2 \\
\hline
\end{tabular}

Table 5. Normalised-weighted grey decision making matrix and solution results $S_{i}$

\begin{tabular}{|c|c|c|c|c|c|c|c|c|c|c|c|c|c|c|}
\hline & $\otimes$ & $\hat{x}_{1}$ & $\otimes$ & $\hat{x}_{2}$ & $\otimes$ & $\hat{x}_{3}$ & $\otimes$ & $\hat{x}_{4}$ & & $\hat{x}_{5}$ & & $\hat{x}_{6}$ & $S_{i}$ & Rank \\
\hline$A_{1}$ & 0.100 & 0.182 & 0.057 & 0.086 & 0.115 & 0.190 & 0.113 & 0.248 & 0.113 & 0.201 & 0.058 & 0.130 & 0.797 & 4 \\
\hline$A_{2}$ & 0.084 & 0.162 & 0.091 & 0.125 & 0.089 & 0.173 & 0.090 & 0.182 & 0.115 & 0.192 & 0.102 & 0.183 & 0.794 & 3 \\
\hline$A_{3}$ & 0.080 & 0.177 & 0.067 & 0.112 & 0.115 & 0.194 & 0.145 & 0.285 & 0.144 & 0.214 & 0.069 & 0.146 & 0.874 & 1 \\
\hline 4 & 0.115 & 0.181 & 0.081 & 0.129 & 0.123 & 0.210 & 0.084 & 0.222 & 0.125 & 0.204 & 0.074 & 0.156 & 0.853 & 2 \\
\hline
\end{tabular}

Table 6. Final ranking of alternatives

\begin{tabular}{|c|c|c|c|c|}
\hline Alt. & $\boldsymbol{S}_{\boldsymbol{i}}$ & $\boldsymbol{P}_{\boldsymbol{i}}$ & $\boldsymbol{Q}_{\boldsymbol{i}}$ & Rank \\
\hline$A_{1}$ & 0.797 & 0.670 & 0.724 & 3 \\
\hline$A_{2}$ & 0.794 & 0.670 & 0.722 & 4 \\
\hline$A_{3}$ & 0.874 & 0.747 & 0.801 & 1 \\
\hline$A_{4}$ & 0.853 & 0.717 & 0.775 & 2 \\
\hline$\lambda$ & $\alpha 3.318$ & $\Sigma 2.805$ & $\lambda=0.423$ & \\
\hline
\end{tabular}




\section{Conclusions}

After processing the given data on decision alternatives as well as attributes and their preferences as GDMM, rational solutions about contractor's selection can be made even in a vague environment. Solution of the presented problem by applying a novel WASPAS-G method shows that alternatives finally ranked as follows: $A_{3}>A_{4}>A_{1}>A_{2}$. While, if taken into account only additive part of the method, alternatives rank $A_{3}>A_{4}>A_{2}>A_{1}$, and if taken into account only exponential part of the method, alternatives are located as follows $A_{3}>A_{4}>A_{1}=A_{2}$ and the final ranking order is not clearly defined.

The proposed novel aggregated WASPAS-G method is a valuable tool for making a more precise decision, considering preferences of stakeholders in an uncertain environment.

\section{REFERENCES}

1. HWANG, B.G., X. ZHAO, M .J. S. GAY, Public Private Partnership Projects in Singapore: Factors, Critical Risks and Preferred Risk Allocation from the Perspective of Contractors, International Journal of Project Management, vol. 31, no. 3, 2013, pp. 424-433.

2. CHENG, Y. M., An Exploration into Cost-influencing Factors on Construction Projects, International Journal of Project Management, vol. 32, no. 5, 2014, pp. 850-860.

3. ABBASIANJAHROMI, H., H. RAJAIE, E. SHAKERI, A Framework for Subcontractor Selection in the Construction Industry, Journal of Civil Engineering and Management, Vol. 19, no. 2, 2013, pp. 158-168.

4. MANU, P., N. ANKRAH, D. PROVERBS, S. SURESH, Mitigating the Health and Safety Influence of Subcontracting in Construction: the Approach of Main Contractors, International Journal of Project Management, vol. 31, no. 7, 2013, pp. 1017-1026.

5. ALHUMAIDI, H., Construction Contractors Ranking Method Using Multiple Decision-Makers and Multiattribute Fuzzy Weighted Average, Journal of Construction Engineering and Management, 2014.
6. WANG, W. CH., W. D. YU , I. T. YANG, CH. CH. LIN, M. T. LEE, Y. Y. CHENG, Applying the AHP to Support the Bestvalue Contractor Selection - Lessons Learned from Two Case Studies in Taiwan, Journal of Civil Engineering and Management, vol. 19(1), 2013, pp. 24-36.

7. OLCER, M. G., D. E. AKYOL, A MADM Based Decision Support System for International Contractor Rating, Journal of Intelligent \& Fuzzy Systems, vol. 27, no. 5 , 2014, pp. 2163-2175.

8. EL-ABBASY, M. S., T. ZAYED, M. AHMED, H. ALZRAIEE, M. ABOUHAMAD, Contractor Selection Model for Highway Projects Using Integrated Simulation and Analytic Network Process, Journal of Construction Engineering and Management, vol. 139, no. 7, 2013, pp. 755-767.

9. BANCIU, D. D. M., M. RESTEANU, MADM Models for Decision Making in Acquisitions, Studies in Informatics and Control, ICI Publishing House, vol. 20, no. 3, 2011, pp. 313-324.

10. ZAVADSKAS, E. K., Z. TURSKIS, R. VOLVACIOVAS, S. KILDIENE, Multicriteria Assessment Model of Technologies, Studies in Informatics and Control, vol. 22(4), 2013, pp. 249-258.

11. ANDREICA, M., C. RESTEANU, R. TRANDAFIR, Parallel and Distributed Software Assessment in Multi-Attribute Decision Making Paradigm, Studies in Informatics and Control, vol. 23(2), 2014, pp. 133-142.

12. ULUBEYLI, S, E. MANISALI, A. KAZAZ, Subcontractor Selection Practices in International Construction Projects, Journal of Civil Engineering and Management, vol. 16(1), 2010, pp. 47-56.

13. ARSLAN, G., Web-based Contractor Evaluation System for Mass-housing Projects in Turkey, Journal of Civil Engineering and Management, vol. 18, no. 3, 2012, pp. 323-334.

14. TSERNG, H. P., P. CH. CHEN, W. H. HUANG, M. CH. LEI, Q. H. TRAN, Prediction of Default Probability for Construction Firms Using the Logit Model, Journal of Civil Engineering and Management, vol. 20(2), 2014, pp. 247-255. 
15. JASKOWSKI, P., S. BIRUK, R. BUCON, Assessing Contractor Selection Criteria Weights with Fuzzy AHP Method Application in Group Decision Environment, Automation in Construction, vol. 19, 2010, pp. 120-126.

16. CHEN, C. T., C. T. LIN, S. F. HUANG, A Fuzzy Approach for Supplier Evaluation and Selection in Supply Chain Management, International Journal of Production Economics, vol. 102, 2006, pp. 289-301.

17. MEHRJERDI, Y. Z., Strategic System Selection with Linguistic Preferences and Grey Information Using MCDM, Applied Soft Computing, vol. 18, 2014, pp. 323-337.

18. DENG J., Control Problems and Grey Systems, Systems and Control Letters, vol. 5, no. 2, 1982, pp. 288-294.

19. CHEN, M. F., G. H. TZENG, Combining Grey Relation and TOPSIS Concepts for Selecting an Expatriate Host Country, Mathematical and Computer Modelling, vol. 40(13), 2004, pp. 1473-1490.

20. LIU, S., Y. LIN, Grey Systems: Theory and Applications, Springer-Verlagh, 2010, Berlin, Heidelberg.

21. TURSKIS, Z., E. K. ZAVADSKAS, V. KUTUT, A Model Based on ARAS-G and AHP Methods for Multiple Criteria Prioritizing of Heritage Value, International Journal of Information Technology \& Decision Making, vol. 12, no. 1, 2013, pp. 45-73.

22. SIOZINYTE, E., J. ANTUCHEVIČIENĖ, V. KUTUT, Upgrading the Old Vernacular Building to Contemporary Norms: Multiple Criteria Approach, Journal of Civil Engineering and Management, vol. 20(2), 2014, pp. 291-298.

23. OZTAYSI, B., A Decision Model for Information Technology Selection Using AHP Integrated TOPSIS-Grey: The Case of Content Management Systems, Knowledge-Based Systems, vol. 70, 2014, pp. 44-54.

24. ZHANG, Z., Y. Y. WANG, Z. X. WANG, A Grey TOPSIS Method Based on Weighted Relational Coefficient, Journal of Grey System, vol. 26(2), 2014, pp. 112-123.
25. KIM, G., Y. JONG, S. F. LIU, Generalized Hybrid Grey Relation Method for Multiple Attribute Mixed Type Decision Making, Journal of Grey System, vol. 26, no. 2, 2014, pp. 142-153.

26. TAVANA, M., E. MOMENI, N. REZAEINIYA, S. M. MIRHEDAYATIAN, H. REZAEINIYA, A Novel Hybrid Social Media Platform Selection Model Using Fuzzy ANP and COPRAS-G, Expert Systems with Applications, vol. 40, no. 14, 2013, pp. 5694-5702.

27. NGUYEN, H. T., S. Z. M. DAWAL, Y. NUKMAN, H. AOYAMA, Hybrid Approach for Fuzzy Multi-attribute Decision Making in Machine Tool Selection with Consideration of the Interactions of Attributes, Expert Systems with Applications, vol. 41, no. 6, 2014, pp. 3078-3090.

28. KUANG, H., D. M. KILGOUR, K. W HIPEL, Grey-based PROMETHEE II with Application to Evaluation of Source Water Protection Strategies, Information Sciences, vol. 294, 2015, pp. 376-389.

29. STANUJKIC, D., N. MAGDALINOVIC, D. MILANOVIC, S. MAGDALINOVIC, G. POPOVIC, An Efficient and Simple Multiple Criteria Model for a Grinding Circuit Selection based on the MOORA method, Informatica, vol. 25, no. 1, 2014, pp. 73-93.

30. STANUJKIC, D., An Extension of the MOORA Method for Solving Fuzzy Decision Making Problems, Technological and Economic Development of Economy, vol. 19, suppl. 1, 2013, pp. 228-255.

31. HASHEMI, S. S, S. H. RAZAVI HAJIAGHA, M. AMIRI, Decision Making with Unknown Data: Development of ELECTRE Method Based on Black Numbers, Informatica, vol. 25 , no. 1,2014 , pp. 21-36.

32. SENTHIL, S., B. SRIRANGACHARYULU, A. RAMESH, A Robust Hybrid Multi-criteria Decision Making Methodology for Contractor Evaluation and Selection in Third-party Reverse Logistics, Expert Systems with Applications, vol. 41, no. 1, 2014, pp. 50-58. 
33. YOU, X. Y., J. X. YOU, H. C. LIU, L. ZHEN, Group Multi-criteria Supplier Selection Using an Extended VIKOR Method with Interval 2-tuple Linguistic Information, Expert Systems with Applications, vol. 42, no. 4, 2015, pp. 1906-1916.

34. ZAVADSKAS, E. K., Z. TURSKIS, J. ANTUCHEVICIENE, A. ZAKAREVICIUS, Optimization of Weighted Aggregated Sum Product Assessment, Electronics and Electrical Engineering $=$ Elektronika ir Elektrotechnika, vol. 122(6), 2012, pp. 3-6.

35. HASHEMKHANI ZOLFANI, S., M. H. AGHDAIE, A. DERAKHTI, E. K. ZAVADSKAS, M. H. M. VARZANDEH, Decision Making on Business Issues with Foresight Perspective; an Application of New Hybrid MADM Model in Shopping Mall Locating, Expert Systems with Applications, vol. 40, no. 17,2013 , pp. 7111-7121.

36. DEJUS, T., J. ANTUCHEVICIENE, Assessment of Health and Safety Solutions at a Construction Site, Journal of Civil Engineering and Management, vol. 19, no. 5, 2013, pp. 728-737.

37. ZAVADSKAS, E. K, J. ANTUCHEVICIENE, SAPARAUSKAS, Z. TURSKIS, MCDM Methods WASPAS and MULTIMOORA: Verification of Robustness of Methods when Assessing Alternative Solutions, Economic Computation and Economic Cybernetics Studies and Research, vol. 47, no. 2, 2013, pp. 5-20.

38. SIOZINYTE, E., J. ANTUCHEVICIENE, Solving the Problems of Daylighting and Tradition Continuity in a Reconstructed Vernacular Building, Journal of Civil Engineering and Management, vol. 19, no. 6, 2013, pp. 873-882.

39. BAGOCIUS, V., E. K. ZAVADSKAS, Z. TURSKIS, Multi-person Selection of the Best Wind Turbine Based on the Multicriteria Integrated Additivemultiplicative Utility Function, Journal of Civil Engineering and Management, vol. 20 , no. 4 , 2014, pp. 590-599.
40. VAFAEIPOUR, M., S. HASHEMKHANI ZOLFANI, M. H. MORSHED VARZANDEH, A. DERAKHTI, M. KESHAVARZ ESHKALAG, Assessment of Regions Priority for Implementation of Solar Projects in Iran: New Application of a Hybrid Multi-criteria Decision Making Approach, Energy Conversion and Management, vol. 86, 2014, pp. 653-663.

41. LASHGARI, S., ANTUCHEVICIENE J, A. DELAVARI, O. KHEIRKHAH, Using QSPM and WASPAS Methods for Determining Outsourcing Strategies, Journal of Business Economics and Management, vol. 15(4), 2014, pp. 729-743.

42. ZAVADSKAS, E. K., J. ANTUCHEVICIENE, S. H. RAZAVI HAJIAGHA, S. S. HASHEMI, Extension of Weighted Aggregated Sum Product Assessment with Interval-valued Intuitionistic Fuzzy Numbers (WASPAS-IVIF), Applied Soft Computing, vol. 24, 2014, pp. 1013-1021.

43. LIU, B., T. HUO, P. LIAO, J. GONG, B. XUE, A Group Decision-Making Aggregation Model for Contractor Selection in Large Scale Construction Projects Based on Two-Stage Partial Least Squares (PLS) Path Modeling, Group Decision and Negotiation, 2014, 10.1007/s10726-014-9418-2.

44. HUANG, W., H. TSERNG, E. JASELSKIS, S. LEE, Dynamic Threshold Cash Flow-Based Structural Model for Contractor Financial Prequalification, Journal of Construction Engineering and Management, vol. 140, no. 10, 2014.

45. PLEBANKIEWICZ, E., Modelling Decision-making Processes in Bidding Procedures with the Use of the Fuzzy Sets Theory, International Journal of Strategic Property Management, vol. 18, no. 3, 2014, pp. 307-316. 